\title{
Comparative Study on Mortality Patterns in Japan and China
}

\author{
Zhao-Chen LI $^{* 1}$, Yuko MORIKAWA*2, Hideaki NAKAGAWA*2 \\ Masaji TABATA*2, Muneko NISHIJO*2, Masami SEMMA*2 \\ Katsuyuki MIURA*2, Katsushi YOSHITA*2, Shunichi KAWANO*2 \\ and $\mathrm{Yu}-\mathrm{Du} \mathrm{CHEN}^{* 1}$ \\ ${ }^{* 1}$ Center of Health Statistics Information, Ministry of Public Health, People's Republic of China
${ }^{* 2}$ Department of Public Health, Kanazawa Medical University, Ishikawa
}

\begin{abstract}
On the basis of the 1990 Chinese death notice data and 1990 Japanese populations vital statistical materials, the mortality patterns and proportions of individual causes of death in the two countries were compared.

In both sexes, the mortality rates were the highest in almost all age groups in Chinese rural areas followed by urban areas and Japan.

In Japan and in Chinese urban areas, malignant neoplasms, cardiovascular diseases and cerebrovascular diseases were the major causes of death, with these three making up about $60 \%$ of the total. In Chinese rural areas, these three conditions were responsible for $43 \%$ of all deaths, a considerably lower figure as compared to those in the other two areas, and the mortality rates for infectious diseases and accident/suicide were higher than those in the other two areas. Of the three major adult diseases, cerebrovascular diseases were found to be especially frequent in both Chinese urban and rural areas. On the other hand, ischemic heart disease was found at comparable levels in Japan and China and the rate was lower than in other developed countries. Site-specific mortality rates for malignant neoplasms were characterized by high rates for lung, liver and esophageal cancers in China. The mortality rates for bronchitis in both Chinese urban and rural areas were markedly higher than those in Japan

These differences in mortality rates and proportions of individual causes of death between China and Japan are thought to be attributable to the differences in medical services and the level of risk factors for each disease.
\end{abstract}

Key words: Vital statistics, Japan, China, Comparative study

\section{Introduction}

Mortality rate is one of the important indices reflecting the standanrd of health in a given region, and is closely connected with the socioeconomic, medical and welfare circumstances of that region. At present, China is undergoing rapid development, while Japan is already an industrially advanced country. In addition, Japan and China both have their own characteris- tic lifestyles, including dietary habits. A number of studies have already focused on the health status in China ${ }^{1 \sim 4)}$, but no comparative study has been done in detail of the mortality patterns in Japan and China. Because China covers such a vast area and its population is so huge, there are many difficulties to collect statistical data on a national scale. Previously collected statistical data have shown problems such as regional bias and a low cover rate versus the entire population.

Reprint requests to: Yuko Morikawa, Department of Public Health, Kanazawa Medical University,

1-1, Daigaku, Uchinada, Ishikawa, 920-02, Japan 
Also, international classifications of causes of death and diseases have not been adopted. So satistics have not been suitable for comparative studies. Recently, however, the Ministry of Public Health of the People's Republic of China has begun to prepare statistical data on mortality for the first time on a national scale in China based on the 9th International Classification of Diseases. In the present study, making use of these materials, we compared the mortality pattern and structure of causes of death in Japan and China.

\section{Materials and methods}

The Center for Health Statistics Information, in the Chinese Ministry of Public Health, has been selecting regions at random to implement a death notice system. In the regions, the cause of death must be certificated by a medical doctor and reported to health service center in each city or prefecture. The number of such regions has been increasing year by year, and as of 1990 included 40 cities (population 56, 863, 043) and 70 rural prefectures (population 42, 836, 397), for a total of $99,699,440$ people amounting to $8.8 \%$ of the national population. For the cities, the major urban areas such as Beijing, Changchun, Tianjin, Shanghai, Nanking and Guangzhou have been selected, and thus almost all major urban areas are included. In addition, 24 other small and medium sized cities and rural prefectures have been selected from all over the country, thus eliminating any geographical bias. From 1987, causes of death have been classified according to the International Classification of Diseases(ICD9) of the WHO in all of the target regions. The data from each region are delivered via each province to the Center for Health Statistics Information of the Ministry of Public Health and totaled.

For comparison of the mortality patterns in China and Japan, the above mentioned data for $1990^{5)}$ were used in the case of China, and the 1990 Population Vital Statistics) (Statistics and Information Department, Minister's Secretariat, Min-

Table 1 Age-sex composition of the population in 1990 .

\begin{tabular}{|c|c|c|c|c|c|c|}
\hline \multirow{2}{*}{ Age class } & \multicolumn{3}{|c|}{ Men } & \multicolumn{3}{|c|}{ Women } \\
\hline & Urban in China & Rural in China & Japan & Urban in China & Rural in China & Japan \\
\hline $0-4$ & 1891418 & 1925352 & 3317367 & 1790615 & 1758214 & 3152423 \\
\hline $5-9$ & 1993204 & 1834839 & 3810008 & 1890151 & 1681190 & 3626648 \\
\hline $10-14$ & 1924846 & 2047967 & 4358230 & 1818723 & 1903155 & 4137679 \\
\hline $15-19$ & 2493022 & 2341105 & 5107977 & 2286017 & 2241831 & 4859735 \\
\hline $20-24$ & 2858592 & 2168016 & 4437613 & 2484774 & 2136316 & 4283828 \\
\hline $25-29$ & 3278262 & 1991489 & 4035709 & 2984482 & 1943280 & 3940802 \\
\hline $30-34$ & 3101030 & 1767743 & 3891907 & 2909759 & 1689816 & 3821102 \\
\hline $35-39$ & 2518592 & 1637904 & 4499773 & 2337183 & 1558134 & 4446124 \\
\hline $40-44$ & 1892111 & 1314634 & 5333198 & 1760901 & 1229992 & 5284445 \\
\hline $45-49$ & 1559997 & 1067790 & 4471972 & 1490236 & 981569 & 4517682 \\
\hline $50-54$ & 1532499 & 935443 & 3990975 & 1483416 & 869264 & 4077648 \\
\hline $55-59$ & 1428318 & 842074 & 3781532 & 1353925 & 809540 & 3932241 \\
\hline $60-64$ & 1087403 & 702122 & 3234444 & 1047472 & 700079 & 3501226 \\
\hline $65-69$ & 757850 & 537074 & 2189318 & 781119 & 582043 & 2901553 \\
\hline $70-74$ & 481090 & 349686 & 1556586 & 547097 & 429603 & 2253254 \\
\hline $75-79$ & 272485 & 198097 & 1196534 & 365895 & 286666 & 1817939 \\
\hline $80-84$ & 117517 & 91856 & 678463 & 197806 & 164859 & 1153257 \\
\hline $85^{-}$ & 44269 & 37647 & 357363 & 100940 & 80008 & 764842 \\
\hline Total & 29232505 & 21790838 & 60248969 & 27630521 & 21045559 & 62472428 \\
\hline
\end{tabular}


istry of Health and Welfare, Japan, 1992) in the case of Japan. Table 1 shows the populations of Japan and China in 1990.

Adjusted mortality rates were determined by the direct method with the 1985 total Japan population model used as the standard population.

\section{Results}

\section{Comparison of mortality rates according to age group}

Table 2 shows crude and age-adjusted mortality rates according to region. Crude mortality rates for the entire population, men, and women were all highest in Japan. However, adjusted mortality rates per 100,000 population were 1,111 . 7 for men in Chinese urban areas and 1,186.0 for men in Chinese rural areas, rates approximately 1.5- and 1.6-fold higher than the corresponding Japanese rates. Similarly, for Chinese women, the rates were 772.6 and 815.8 for urban and rural areas respectively, about 1.8- and 1.9-fold higher than the corresponding Japanese rates.

Figures 1 and 2 illustrate mortality rates according to sex and age in Chines urban and rural areas and in Japan. Comparing Chinese urban areas and Japan, rates for men in the 15-19, 20-24 and 45-49-year-old groups were higher in the latter, whereas those for the other age groups were higher in the former. On the other hand, comparing Chinese rural areas and Japan, mortality rates were higher for all age groups in the former. For women as well, mortality rates in

Table 2 Comparison of Mortality Rates in China and Japan (1990).

\begin{tabular}{|c|c|c|c|c|c|c|c|c|c|}
\hline \multirow{3}{*}{ Mortality Rate \# } & \multicolumn{3}{|c|}{ Total } & \multicolumn{3}{|c|}{ Men } & \multicolumn{3}{|c|}{ Women } \\
\hline & \multicolumn{2}{|c|}{ China } & \multirow[t]{2}{*}{ Japan } & \multicolumn{2}{|c|}{ China } & \multirow[t]{2}{*}{ Japan } & \multicolumn{2}{|c|}{ China } & \multirow[t]{2}{*}{ Japan } \\
\hline & Urban & Rural & & Urban & Rural & & Urban & Rural & \\
\hline Crude & 585.1 & 643.3 & 668.4 & 621.0 & 688.1 & 736.5 & 547.1 & 596.9 & 602.8 \\
\hline Standardized* & 922.7 & 982.1 & 561.1 & 1111.7 & 1186.0 & 747.9 & 772.6 & 815.8 & 423.0 \\
\hline
\end{tabular}

\#: annual rates per 100,000 population

*: mortality rate standardized by the direct method to the age distribution in 5-year age groups of the total Japanese population model in 1985

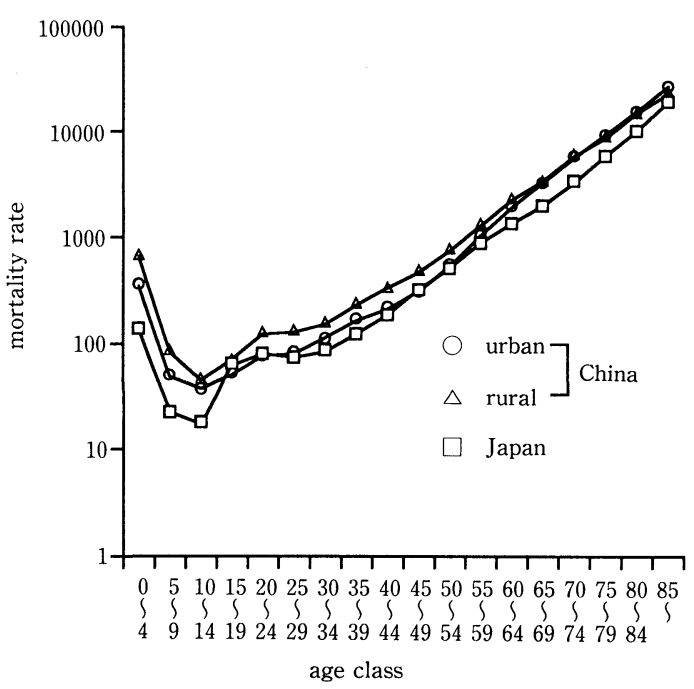

Fig. 1 Mortality Rates of Men (per 100,000 population).

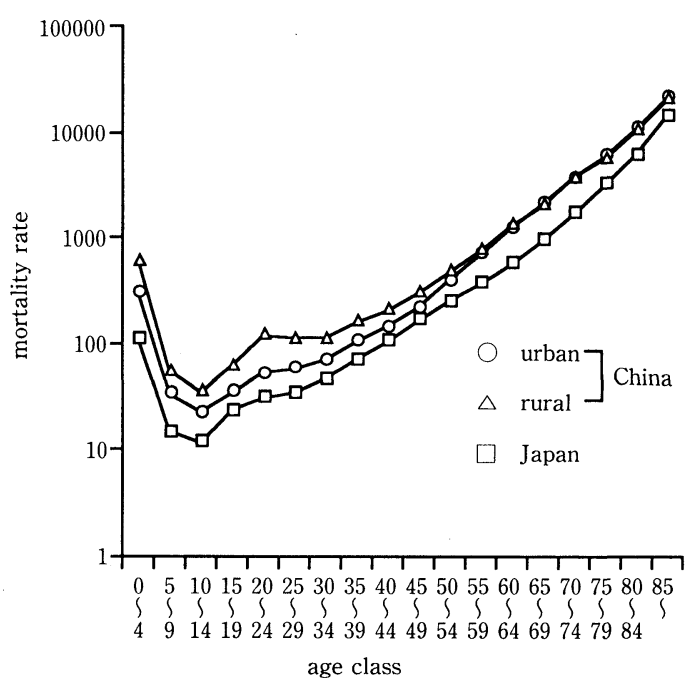

Fig. 2 Mortality Rates of Women (per 100,000 population). 
both Chinese urban and rural areas were higher than those in Japan in all age groups.

In the comparison of Chinese urban and rural areas, mortality rates for men were higher in the latter between 0 and 74 year, but higher in the former for those aged 75 years and over. For women, mortality rates were higher in rural as compared to urban areas in the age groups 0-64 years and 70-74 years, but higher in the urban areas in the 65-69 and $\geq 75$-year-old groups.

\section{Order of causes of death}

Table 3 shows the order of causes of death and the proportion of deaths due to each cause. In Japan the first cause of death for the both sexs was malignant neoplasms, followed by cardiovascular diseases in second place, and cerebrovascular diseases in third, with these three causes of death accounting for $61.4 \%$ of the total. In Chinese urban areas, malignant neoplasms were the first cause of death followed by cerebrovascular diseases in second place and cardiovascular diseases in third, with these three causes of death accounting for $57.6 \%$ of the total. In Chinese rural areas, the cause of death was bronchitis, followed by malignant neoplasms in second place, and cerebrovascular diseases in third. Malignant neoplasms, cerebrovascular diseases, and cardiovascular diseases accounted for $43.5 \%$ of the total deaths in this population, a figure considerably lower than the corresponding figures in the Japanese and Chinese urban populations. Looking at the order of deaths according to sex, in Chinese urban areas and in Japan the order of causes of death was the same for both men and women as with both sexes combined. In the Chinese rural areas, malignant neoplasms, bronchitis and cerebrovascular diseases were the first, second and third causes of death in men, while in the women the corresponding order was bronchitis, cerebrovascular diseases and malignant neoplasms.

3. Mortality rates for selected causes of death in each age class (Table 4, Table 5)

The mortality rates for infectious diseases were higher in China, particularly in rural areas, than in Japan for both sexes in all age groups. The mortality rates for accident and suicide were higher in Chinese rural areas than the others in almost all age groups. The mortality rates for pneumonia in the groups aged $0-19$ years and the mortality rates for bronchitis in the groups aged 40-59, 60-79 and 80 and over years were markedly higher in China, particularly in rural areas, than Japan for both sexes. On the other hand, those for pneumonia in the age groups aged 60-79 and 80 and over were higher in Japan than in China. In the groups aged 60-79 and 80 and over, the mortality rates for cerebrovascular diseases were higher in China than in Japan. The mortality rates for malignant neoplasms and heart diseases were not different among three areas.

\section{Age-adjusted mortality rates for major causes of death}

The age-adjusted mortality rates for major causes of death are outlined in Table 6 . The age-adjusted mortality rates for malignant neoplasms were highest for both sexes in Chinese urban areas, followed by Chinese rural areas and Japan, with the differences among the areas being relatively small (men: 242.4, 223.5 and 215.6 respectively; women: $130.8,116.0$ and 107.7 respectively). The adjusted mortality rates for cerebrovascular diseases were highest for both sexes in Chinese urban areas, followed by Chinese rural areas and Japan, with the rates in China $\geq 2$-fold those in Japan (men: 242.4, 211.8 and 97.9; women: 172.0, 154.4 and 68.6). The adjusted mortality rates for cardiovascular diseases were higher for both sexes in Chinese urban areas than in Japan, but similar in Chinese rural areas and Japan. The adjusted mortality rates for bronchitis were markedly higher in China than in Japan, with the difference between Chinese urban and rural areas also being large (Chinese rural areas, Chinese urban areas, Japan: 271.1, 166.6 and 16.6 in men, and 189.4, 111.3 and 5.8 in women respectively). The adjusted mortality rates for infectious diseases and accident and suicide were higher in 
日衛誌 (Jpn. J. Hyg.) 第 49 巻 第 5 号 1994 年 12 月

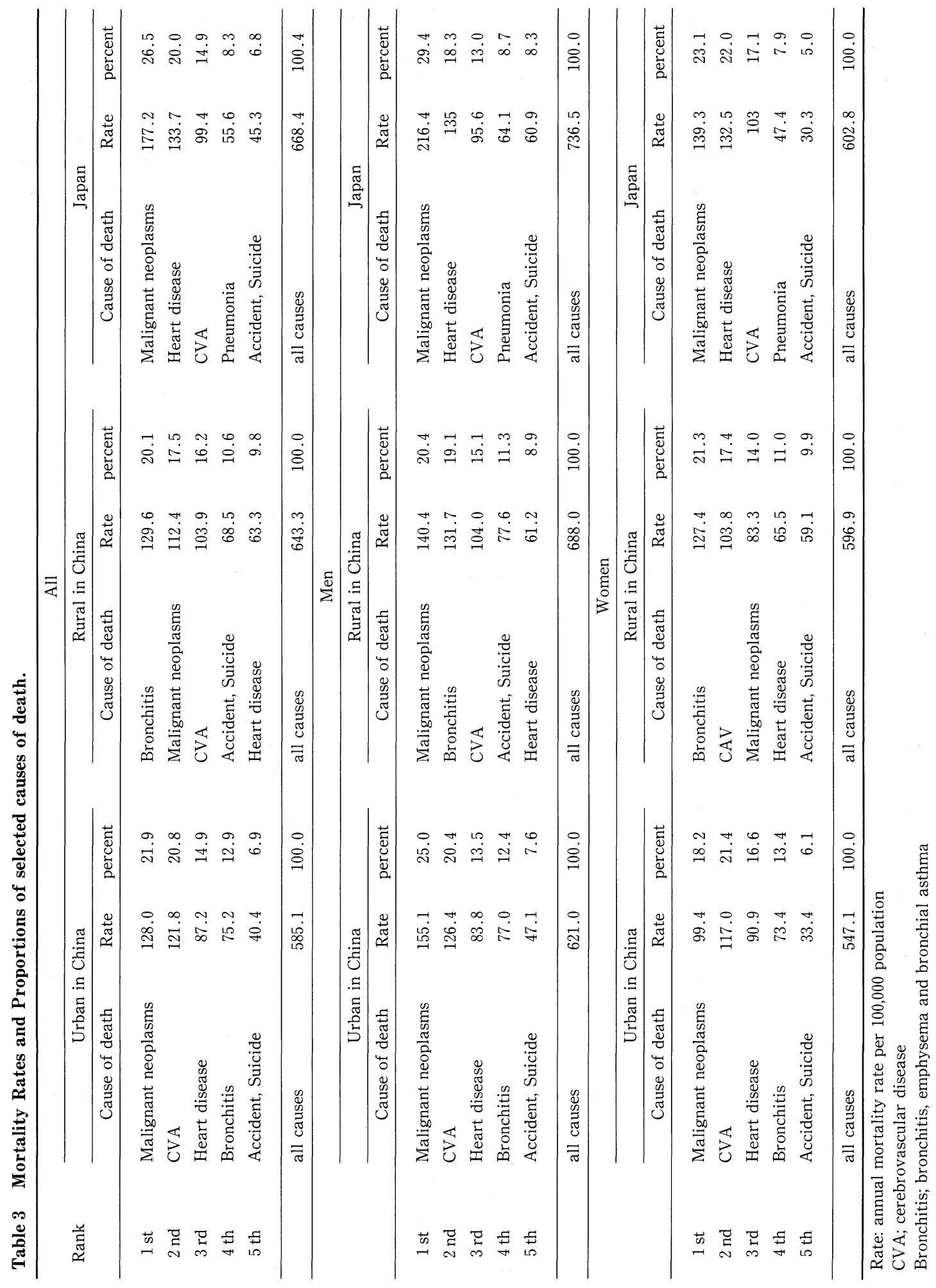


日衛誌(Jpn. J. Hyg.) 第 49 巻第 5 号 1994 年 12 月

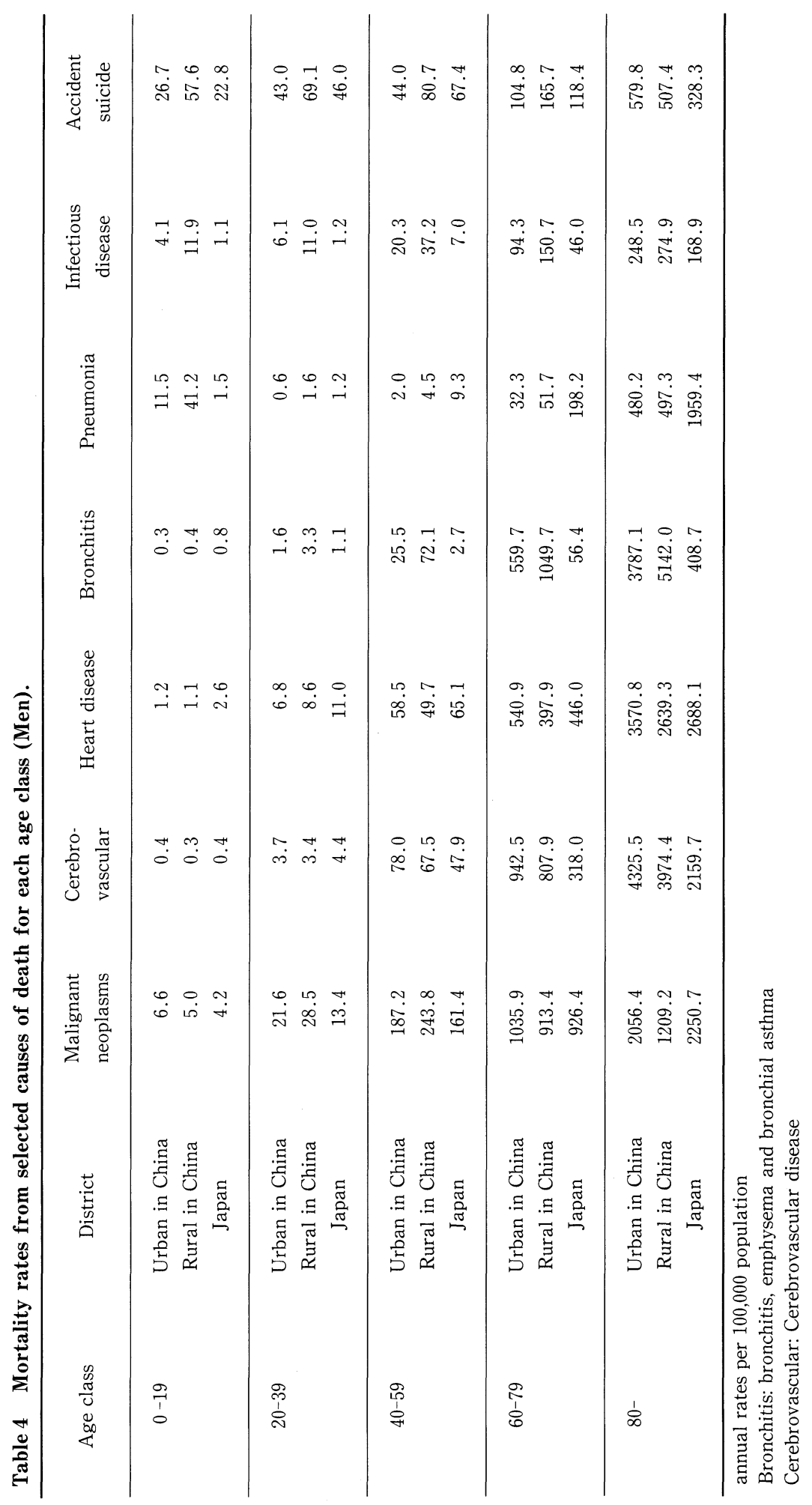


日衛誌(Jpn. J. Hyg.) 第 49 巻 第 5 号 1994 年 12 月

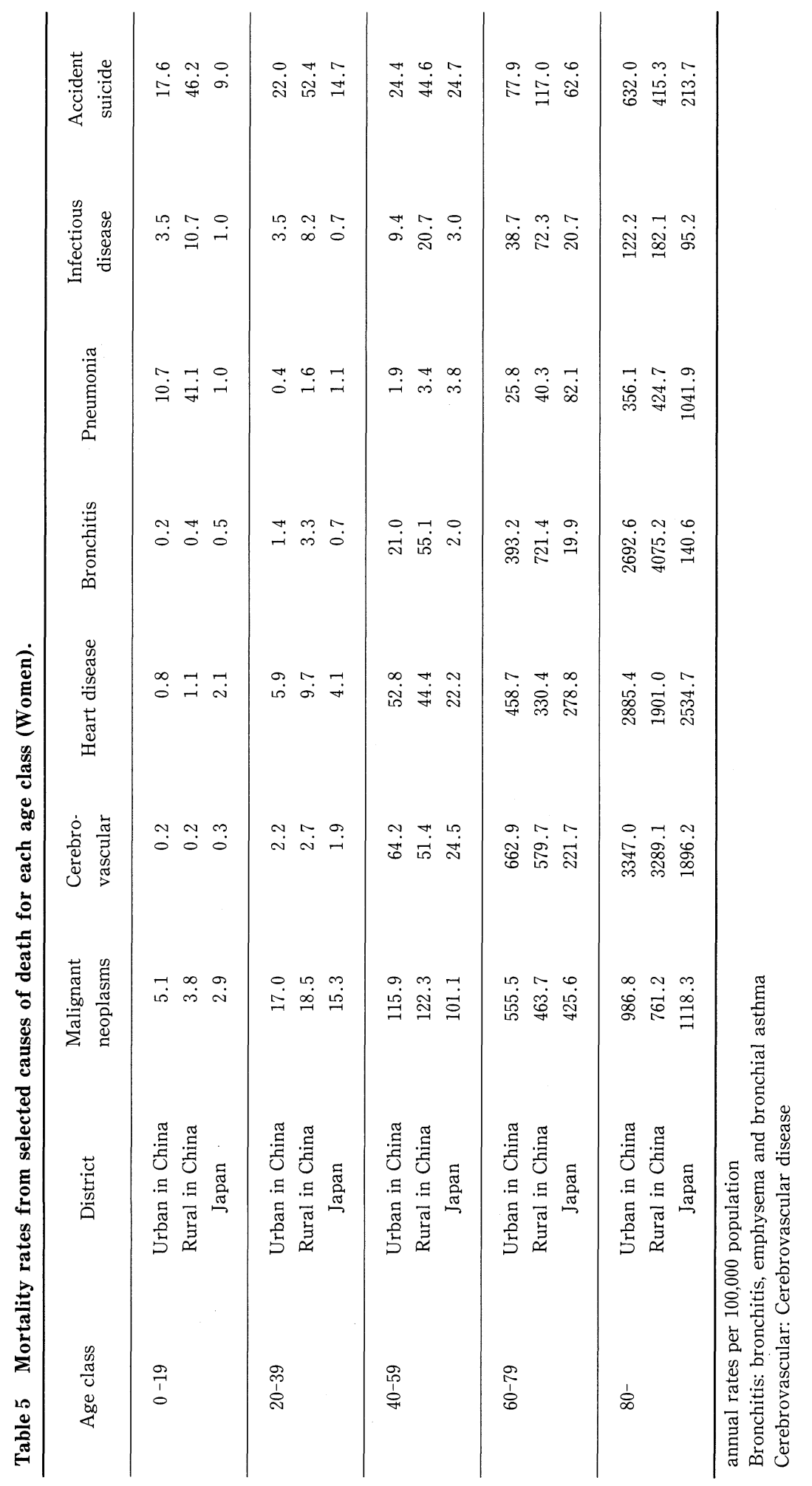


Table 6 Standardized mortality rates from selected causes of death (1990).

\begin{tabular}{|c|c|c|c|c|c|c|}
\hline \multirow{3}{*}{ Cause } & \multicolumn{3}{|c|}{ Men } & \multicolumn{3}{|c|}{ Women } \\
\hline & \multicolumn{2}{|c|}{ China } & \multirow[b]{2}{*}{ Japan } & \multicolumn{2}{|c|}{ China } & \multirow[b]{2}{*}{ Japan } \\
\hline & Urban & Rural & & Urban & Rural & \\
\hline Malignant neoplasms & 242.4 & 223.5 & 215.6 & 130.8 & 116.0 & 107.7 \\
\hline Cerebrovascular disease & 244.9 & 211.8 & 97.9 & 172.0 & 154.4 & 68.6 \\
\hline Heart disease & 168.7 & 125.2 & 132.4 & 133.3 & 95.3 & 87.4 \\
\hline Hypertensive disease & 21.2 & 23.5 & 5.9 & 18.8 & 18.0 & 5.8 \\
\hline Pneumonia & 19.0 & 30.8 & 67.1 & 14.1 & 26.9 & 30.1 \\
\hline Bronchitis & 166.6 & 271.1 & 16.6 & 111.3 & 189.4 & 5.8 \\
\hline Liver cirrhosis & 19.2 & 25.0 & 18.3 & 9.4 & 11.5 & 6.5 \\
\hline Diabetes Mellitus & 10.9 & 4.5 & 7.5 & 13.8 & 4.5 & 5.7 \\
\hline Infectious disease & 26.7 & 43.1 & 12.0 & 12.1 & 24.2 & 5.7 \\
\hline Accident and suicide & 58.9 & 91.4 & 59.9 & 40.7 & 63.8 & 25.5 \\
\hline All causes & 1111.7 & 1186.0 & 747.9 & 772.6 & 815.8 & 423.0 \\
\hline
\end{tabular}

annual rates per 100,000 population

mortality rates standardized by direct method to the age distribution in 5-year age groups of the total Japanese population model in 1985

Bronchitis; bronchitis, emphysema and bronchial asthma

Table 7 Standardized mortality rates from selected malignant neoplasms (1990).

\begin{tabular}{|c|c|c|c|c|c|c|}
\hline \multirow[t]{2}{*}{ Neoplasms } & \multicolumn{3}{|c|}{ Men } & \multicolumn{3}{|c|}{ Women } \\
\hline & \multicolumn{2}{|c|}{ China } & \multirow[b]{2}{*}{ Japan } & \multicolumn{2}{|c|}{ China } & \multirow[b]{2}{*}{ Japan } \\
\hline site & Urban & Rural & & Urban & Rural & \\
\hline Esophagus & 22.6 & 43.3 & 9.8 & 8.3 & 22.3 & 1.5 \\
\hline Stomach & 45.8 & 54.5 & 49.6 & 19.6 & 26.6 & 21.6 \\
\hline Rectum & 13.7 & 9.3 & 9.1 & 10.7 & 7.2 & 4.6 \\
\hline Liver & 40.2 & 51.6 & 29.4 & 14.4 & 18.6 & 8.4 \\
\hline Lung & 67.8 & 34.8 & 45.0 & 29.6 & 12.1 & 11.6 \\
\hline Breast & - & - & - & 8.4 & 4.1 & 8.2 \\
\hline Uterus & - & - & - & 4.1 & 5.0 & 5.9 \\
\hline
\end{tabular}

annual rates per 100,000 population

mortality rates standardized by direct method to the age distribution in 5 -year age groups of the total Japanese population model in 1985

Chinese rural areas than in the others.

\section{Age-adjusted mortality rates for malignant} neoplasms according to site (Table 7)

The first and second most common sites of malignant neoplasms resulting in death in men were the lung and stomach in Chinese urban areas, stomach and liver in Chinese rural areas and stomach and lung in Japan. In women, these were the lung and stomach in Chinese urban areas, stomach and esophagus in Chinese rural areas and stomach and lung in Japan.
Although mortality due to stomach cancer was highest in Chinese rural areas, the differences between Chinese rural areas, Chinese urban areas and Japan were not great. Mortality due to lung cancer was highest in both sexes in Chinese urban areas, with a large difference particularly in women. Mortalities due to liver cancer and esophageal cancer were higher in China as compared to Japan, particularly in the rural areas. No difference in uterine cancer mortality was noted among the three areas, while breast 
Table 8 Standardized motality rates from each type of heart diseases (1990).

\begin{tabular}{|c|c|c|c|c|c|c|}
\hline \multirow[t]{2}{*}{ Heart disease } & \multicolumn{3}{|c|}{ Men } & \multicolumn{3}{|c|}{ Women } \\
\hline & \multicolumn{2}{|c|}{ China } & \multirow[b]{2}{*}{ Japan } & \multicolumn{2}{|c|}{ China } & \multirow[b]{2}{*}{ Japan } \\
\hline type & Urban & Rural & & Urban & Rural & \\
\hline Rheumatic & 8.0 & 9.7 & 0.7 & 13.7 & 13.0 & 1.1 \\
\hline Ischemic & 49.3 & 24.2 & 45.4 & 45.6 & 21.2 & 38.6 \\
\hline AMI & 22.7 & 14.3 & 29.7 & 17.7 & 10.8 & 22.5 \\
\hline
\end{tabular}

annual rates per 100,000 population

mortality rates standardized by direct method to the age distribution in 5-year age groups of the total Japanese population model in 1985

AMI; acute myocardial infarction

cancer mortality tended to be lower in the Chinese rural areas as compared to Chinese urban areas and Japan.

\section{Age-adjusted mortality rates according to type of cardiovascular disease (Table 8)}

In China, in both urban and rural areas, mortality rates for chronic rheumatic heart disease were higher than in Japan. Mortality rates for ischemic heart disease were approximately the same in Chinese urban areas and Japan, but tended to be lower in Chinese rural areas.

\section{Discussion}

It was clarified in this study that mortality rates were higher in China than in Japan and that within China itself they were higher in rural areas than in urban areas. Particularly the mortality rates for bronchitis, cerebrovascular diseases and acute diseases such as infectious diseases and accident/suicide were markedly higher in China than in Japan. In contrast, the mortality rates for malignant neoplasmas and heart diseases did not differ among the three areas and those for ischemic heart disease were almost same among the three areas and being lower than in other developed countries ${ }^{7}$.

In part, the high mortality rates in China, particularly for infectious diseases, bronchitis and accidents, might be caused by the low availability of medical facilities and medical workers and their utilization. In Japan, the numbers of hospital beds, physicians and nurses per 100,000 population in 1986 were 641, 212 and 526 respectively $^{8)}$. In contrast, based on data from a 1985 survey the corresponding figures in Chinese urban areas were 454, 215 and 185 and in Chinese rural areas 153,32 , and $30^{5}$. These differences between Japan and Chinese urban areas were small, whereas Chinese rural areas were considerably poorer than the other two areas. Also, based on the 1984 Chinese Rural Medical Service Survey9), 1985 Chinese Urban Medical Service Survey ${ }^{10)}$ and a survey conducted by Sugaya et al. ${ }^{11)}$ in Japan, the frequency of medical service utilization in Chinese rural areas was 2.6 times per year per person, whereas it was 4 times in Chinese urban areas, and 21 times in Japan. These differences might make it difficult to cure particularly acute diseases such as infectious diseases and to treat accident victims and prevent and control chronic diseases, such as cerebrovascular diseases and bronchitis.

Additionally, the differences in the mortality rates among the three areas could be caused by the differences in the risk factor levels for each disease. The mortality rates for bronchitis were extremely high in China, especially in rural areas. Since the diagnostic criteria was not clear, this might include some cases of pneumonia as bronchitis. However, even taking this into consideration, its mortality rates were extremely high in China. In Japan, a number of studies have described the association between chronic bronchitis and air pollution ${ }^{12), 13)}$. Because coal has been 
the major source of energy in China, development of coal-using industries has caused severe air pollution, particularly in urban areas ${ }^{14)}$ and coal use for cooking and heating has caused indoor air pollution ${ }^{15}$. Some reports have suggested that this air pollution in China is related to chronic obstructive lung diseases ${ }^{16}$. The higher rates in rural areas compared to urban areas might be partly caused by the poor medical environment as mentioned above.

In China, the mortality rates for cerebrovascular diseases were higher than in Japan. It was reported that prevalence, morbidity and mortality rates all differed widely according to area in China ${ }^{17)}$ but no adequate epidemiological studies on the risk factors for stroke such as prevalence of hypertension on a national scale have been conducted. Thus the excess deaths for cerebrovascular diseases in China could not be sufficientry clarified.

The mortality rates for malignant neoplasms did not differ greatly between China and Japan. However site-specific mortality rates showed regional differences. The mortality rates for lung cancer were higher for both sexes in Chinese urban areas than in Japan or Chinese rural areas and those for liver and esophageal cancer were higher in both areas in China than in Japan. Smoking has been determined to be a major cause of lung cancer in China as in Japan ${ }^{18}$. The smoking prevalence in 1984 was not different between Japan and China, that is, almost $60 \%$ for males and $10 \%$ for females ${ }^{19), 20)}$. This smoking prevalence has gradually decreased in Japan ${ }^{19)}$. In contrast, cigarette consumption in China increased annually from the early 1950s to $1987^{20)}$, but the change of the smoking prevalence was not reported. Although the excess deaths due to lung cancer in Chinese urban areas could not be explained by comparing annual smoking prevalences in the two countries, the accumulated effects of smoking should be considered ${ }^{21}$. As for malignancy of the liver, although the mortality rates in Japan are higher than in Western countries $^{7}$, China exceeded Japan, particularly in rural regions. A similar tendency was found for liver cirrhosis. The carrier state of hepatitis B virus is known to be a risk factor for liver cirrhosis and hepato-cellular carcinoma and it was reported that the prevalence of hepatitis $\mathrm{B}$ virus carriers in China was approximately $10 \%$ and thus higher than in Japan ${ }^{22), 23}$. Referring to breast cancer, the mortality rates in Chinese urban areas and in Japan were at the same level and higher than in rural areas. Westernized life style is known to be a risk factor for breast cancer in Japan and geographically the mortality rates in big towns were higher than in small towns ${ }^{24)}$.

Several decades ago, the mortality rates for infectious diseases and cerebrovascular diseases were also extremely high in Japan ${ }^{25)}$. Those have been improved by many control measures against these diseases. For cerebrovascular diseases for example, some systematic studies revealed hypertension to be a major risk factor and control measures against hypertension could have decreased the incidence and the mortality rates for these diseases ${ }^{26)}$. For improvement of the mortality rates in China, future studies on a national scale of the factors responsible for each disease will be important.

\section{Abstract}

On the basis of the 1990 Chinese death notice data and 1990 Japanese population vital statistical materials, the mortality patterns and proportions of individual causes of death in the two countries were compared.

In both sexes, the mortality rates were highest in almost all age groups in Chinese rural areas followed by Chinese urban areas and Japan.

In Japan and in Chinese urban areas, malignant neoplasms, cardiovascular diseases and cerebrovascular diseases were the major causes of death, with these three making up about $60 \%$ of the total. In Chinese rural areas, these three conditions were responsible for $43 \%$ of all deaths, 
a considerably lower figure as compared to those in the other two areas, and the mortality rates for infectious diseases and accident/suicide were higher than those in the other two areas. Of the three major adult diseases, cerebrovascular diseases were found to be especially frequent in both Chinese urban and rural areas. On the other hand, ischemic heart disease was found at comparable levels in Japan and China and the rate was lower than in other developed countries. Sitespecific mortality rates for malignant neoplasms were characterized by high rates for lung, liver and esophageal cancers in China. The mortality rates for bronchitis in both Chinese urban and rural areas were markedly higher than those in Japan.

These differences in mortality rates and proportions of individual causes of death between China and Japan are thought to be attributable to the differences in medical services and the level of risk factors for each disease.

\section{References}

1) Hayase, Y.: Chugoku no jinkoudoutai [Vital statistics in China], J. Health and Welfare Statistics, 36, 24-30 (1989). (in Japanese)

2) Kuroda, T.: Chugoku no jinko to jumyou [Population and life span in China], Igaku no Ayumi, 132, 1063-1067 (1985). (in Japanese)

3 ) Sato, R. and Hayase, K.: A study on the proximate determinants of fertility decline in China, Jpn. J. Health Hum. Ecol., 56, 131-141 (1990). (in Japanese with English abstract)

4 ) Mei, J.M., Minowa, M. and Mori, K.: Nicchukan kenkousuijun no hikaku [A comparison of health level between Japan and China], J. Health and Welfare Statistics, 37, 17-20 (1990). (in Japanese)

5 ) Ministry of Public Health, People's Republic of China: Chinese health statistical digest (1990). (in Chinese)

6 ) Statistics and Information Department, Minister's Secretariat, Ministry of Health and Welfare: 1990 Vital statistics, Health and
Welfare Statistics Association, Tokyo (1992). (in Japanese).

7 ) WHO: World health statistics annual (1992).

8 ) Health and Welfare Statistics Association: Kokumineisei no doukou [Trend of health in Japan], J. Health and Welface Statistics, 38, 466-469 (1991). (in Japanese)

9 ) Ministry of Public Health, People's Republic of China: The data of investigation on medical services among rural districts in China (1986).

10) Ministry of Public Health, Peoples of Republic in China: The data of investigation on medical services among urban districts in China (1989).

11) Sugaya, R., Matsui, K. and Kawaguchi, T.: Nihon no iryou to oubei no iryou no hikaku [Comparison of medical services between Japan and Europe and America], J. Health and Welfare Statistics, 37, 8-13 (1990). (in Japanese)

12) Tani, S.: Epidemiological study on chronic bronchitis, J.J.P.H., 22, 431-438 (1975). (in Japanese with English abstract)

13) Tsunetoshi, Y., Yamaguchi, Y., Nakayama, N. and Ueda, M.: Correlation of air pollution and chronic respiratory symptoms, J.J.P.H., 24, 293-300 (1977). (in Japanese with English abstract)

14) Hao, Q.: Present status of the acid rain problem in China and tasks for the period ahead, J. Japan Soc. Air Pollut., 26, 283-291 (1991). (in Japanese with English abstract)

15) Liu, Q.L., Sasco, A.J., Riboli, E. and Hu, M. $\mathrm{X}$.: Indoor air pollution and lung cancer in Guanghou, People's Republic of China, Am. J. Epidemiol., 137, 145-154 (1993).

16) Tao, X., Hong, C.J., Yu, S., Chen, B., Zhu, H. and Yang, M.: Priority among air pollution factors for preventing chronic obstructive pulmonary disease in Shanghai, Sci. Total Environ., 127, 57-67 (1992).

17) Xue, G.B., Yu, B.X., Wang, X.Z., Wang, G.Q. and Qang, Z.Y.: Stroke in urban and rural 
areas of China, Chin. Med. J., 104, 679-704 (1991).

18) Liu, Z.Y.: Smoking and lung cancer in China, combined analysis of eight case-control studies, Int. J. Epidemiol., 21, 197-201 (1992).

19) Oda, S.: Zenkokureberu no kitsuenritsutyousa no hikaku niyoru nihonjin no kitsuenritsu no kentou [A study of smoking prevalance with comparison of the studies in a national scale], J. Health and Welface Statistics, 37, 11-16 (1990). (in Japanese)

20) Yu, J.J., Mattson, M.E., Boyd, G.M., Mueller, M.D., Shopland, D.R., Pechacek, T.F. and Cullen, J.W.: A comparison of smoking patterns in the people's Republic of China with the United States, JAMA, 264, 1575-1579 (1990).

21) Sobue, T.: Trend of lung cancer, CRC, 2, 844 -852 (1993). (in Japanese with English abstract)

22) Nishioka, K., Levin, A.G. and Simons, M.J.: Hepatitis B antigen, antigen subtypes and hepatitis B antibody in normal subjects and patients with liver disease, Bull. World Hlth. Organ., 52, 293-300 (1975).

23) Wen, Y.M., Xu, Z.Y. and Melnick, J.L.: Viral hepatitis in China, problem and control strategies, pp.99-110, Karger, New York (1992).

24) Kato, I., Tominaga, S. and Kuroishi, T.: Relationship between westernization of dietary habits and mortality for breast and ovarian cancers in Japan, Jpn. J. Cancer Res., 78, 349-357 (1987).

25) Health and Welfare Statistics Association: Kokumineisei no doukou [Trend of health in Japan], J. Health and Welfare Statistics, 31, 107-114 (1991). (in Japanese)

26) Tanigaki, M., Shimamoto, T., Konishi, M., Ueshima, H., Nakanishi, N., Iida, M., Ozawa, H., Kojima, S. and Komachi, Y.: The effect of community control of hypertension on incidence rates for stroke in 8 populations in Japan, J.J.H., 28, 123-135 (1981). (in Japanese with English abstract)

（受付 1994 年 5 月 23 日 受理 1994 年 9 月 13 日） 